\title{
Toxicity of single steroid hormones and their mixtures toward the cyanobacterium Microcystis aeruginosa
}

\author{
Karolina Czarny $^{1}$ (D) $\cdot$ Dominik Szczukocki $^{1} \cdot$ Barbara Krawczyk $^{1} \cdot$ Renata Gadzała-Kopciuch $^{2} \cdot$ Sławomira Skrzypek $^{1}$
}

Received: 13 April 2019 / Revised and accepted: 17 July 2019/Published online: 31 July 2019

(C) The Author(s) 2019

\begin{abstract}
Several compounds, such as hormones, are released uncontrolled into the aquatic environment, and some of these pollutants have an adverse effect on endocrine systems of humans and other organisms. However, there is insufficient information about the effect of natural and synthetic hormones on non-target organisms, such as cyanobacteria. Therefore, in this study, the adverse effects of hormones, singly and in combination, on Microcystis aeruginosa were explored for the first time. Chronic toxicity was evaluated based on biomass and chlorophyll $a$ measurements during 14 days of exposure. Growth of cyanobacteria after exposure to $0.1-100 \mathrm{mg} \mathrm{L}^{-1}$ of hormones was inhibited in a concentration-dependent manner. In most cases, a low concentration of hormones (0.1-1 $\left.\mathrm{mg} \mathrm{L}^{-1}\right)$ did not affect the growth of cyanobacteria, but a higher concentration $\left(>10 \mathrm{mg} \mathrm{L}^{-1}\right)$ inhibited the growth. The obtained 14-day EC $_{50}$ values were $88.92-355.15 \mathrm{mg} \mathrm{L}^{-1}$. According to these values, the decreasing order of the toxicity of the eight hormones to tested cyanobacteria was $17-\alpha$-ethinylestradiol $>$ progesterone $>17 \beta$-estradiol $>5$-pregnen-3 $\beta$ ol-20-one $>$ testosterone $>$ estrone $>$ levonorgestrel $>$ estriol. Moreover, data show that mixed hormones were more toxic than single compounds and more than additive effect was observed. The achieved 14-day $\mathrm{EC}_{50}$ values for mixed hormones were $56.66-166.83 \mathrm{mg} \mathrm{L}^{-1}$. Simultaneous presence of several hormones in the aquatic environment may lead to increased toxicity (more than additive effect) and cause serious ecological effects, more harmful than expected.
\end{abstract}

Keywords Microcystis aeruginosa $\cdot$ Cyanobacteria $\cdot$ Hormones $\cdot$ Endocrine-disrupting chemicals $\cdot$ Aquatic pollution $\cdot$ More than additive effect

\section{Introduction}

Endocrine-disrupting chemicals (EDCs) are substances destabilizing the endocrine system of organisms (Matsushima 2018; Luo et al. 2019). They are considered extremely dangerous substances because they have a harmful effect on reproductive, nervous, and immune systems (Czarny et al. 2017). Their mechanisms of action rely on their ability to

Electronic supplementary material The online version of this article (https://doi.org/10.1007/s10811-019-01874-x) contains supplementary material, which is available to authorized users.

Karolina Czarny

karolina.czarny@ chemia.uni.lodz.pl

1 Laboratory of Environmental Threat, Department of Inorganic and Analytical Chemistry, Faculty of Chemistry, University of Lodz, Tamka 12 Street, 91-403 Lodz, Poland

2 Department of Environmental Chemistry and Bioanalytics, Faculty of Chemistry, Nicolaus Copernicus University, Gagarina7 Street, 87-100 Torun, Poland mimic the action of endogenous hormones, antagonism with the synthesis of normal hormones or their metabolism, and modification of the level of hormone receptors (Annamalai and Namasivayam 2015). Due to their prevalence in the environment, as well as their ability to interfere with the endocrine system, these compounds have, in the past decade, gained popularity among scientific communities. The presence of endocrine disruptors in the aquatic environment has become a serious problem, as these compounds may induce negative effects on the hormonal functions of humans and other organisms (Nie et al. 2015; Jia et al. 2019). They lead to reduced fertility as well as problems with development and growth (Aris et al. 2014; Laurenson et al. 2014). EDCs include naturally produced compounds, such as estrogens, progestogens, androgens, and phytoestrogens, as well as a wide range of industrial chemicals and household products (synthetic hormones, polycyclic aromatic hydrocarbons, polychlorinated compounds, alkylphenols, pharmaceuticals, and pesticides). Endocrine disruptors are present in various aquatic matrices (surface waters (Pojana et al. 2007; Gorga et al. 2015), groundwater (Barber et al. 2009; Li et al. 2015), wastewater 
(Barber et al. 2006; Chang et al. 2011; Yu et al. 2013), and drinking water (Benotti and Snyder 2009)) at trace concentra-

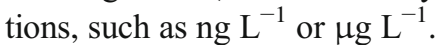

EDCs have negative effects on aquatic organisms, and therefore, more attention is paid to the occurrence of steroid hormones in the environment. Even low concentrations of hormones (ng L ${ }^{-1}$ ) can cause serious disturbances in the functioning of the endocrine system (Khanal et al. 2006; Leonard et al. 2017). It has been proven that their presence in waters can lead to the inhibition of reproductive processes, distortion of gonads, reduction of sperm count, hermaphroditism, and even to the feminization of male fish (Brian et al. 2007; He et al. 2018; Thrupp et al. 2018). So far, most attention has been paid to the study of the environmental impact and fate of estrogens; however, less attention has been paid to other steroids, such as progestogens and androgens. Natural hormones are excreted in urine and feces by humans, farm animals, and aquatic organisms. Their amount is determined by gender, stage of growth, pregnancy, the stage of the menstrual cycle, and the use of contraceptives or hormonal drugs (Leet et al. 2011; Wang et al. 2017). On the other hand, synthetic hormones are widely used in contraceptives, therapies, hormone therapy, livestock and aquaculture production (Laurenson et al. 2014). The mechanisms of bringing these compounds to the environment rely on the discharging of agricultural fertilizers flowing from the fields, which enter the surface waters together with municipal sewage. Many studies show that these types of compounds have a high resistance to the degradation process and a tendency to accumulate in sediments and bioaccumulate in fauna and flora. Therefore, it is important to evaluate the potential risks of hormones for aquatic ecosystems.

There is insufficient information about the effect of hormones on the growth of cyanobacteria. Therefore, the aim of this study was to examine the toxic effect of natural steroid hormones (estrone, 17ß-estradiol, estriol, progesterone, 5-pregnen-3 $\beta$-ol-20one, testosterone), which are key compounds in the regulation of female/male reproductive functions, as well as synthetic ones (17- $\alpha$-ethinylestradiol, levonorgestrel), which are often used as an active ingredient in oral contraceptives. In this study, the toxicity of eight single hormones and their combination on Microcystis aeruginosa was investigated for the first time. For this purpose, a toxicity test with single and mixed hormones was performed and the biomass and chlorophyll $a$ content of examined cyanobacteria were determined.

\section{Materials and methods}

\section{Materials and chemicals}

Analytical grade estrone (E1), 17ß-estradiol (E2), estriol (E3), progesterone (PRO), 5-pregnen-3 $\beta$-ol-20-one (PRE), and testosterone (TST) (purity > 98\%) were from Sigma-Aldrich
(Germany), and 17- $\alpha$-ethinylestradiol (EE2) and levonorgestrel (LG) (purity > 97\%) were obtained from TCI (Japan). All of the investigated hormones were dissolved in HPLC grade methanol (Chemsolve, Poland) to prepare a $10 \mathrm{mg} \mathrm{mL}^{-1}$ stock solution and stored at $4{ }^{\circ} \mathrm{C}$ for subsequent experiments.

\section{Microcystis aeruginosa cultures}

The freshwater cyanobacterium Microcystis aeruginosa PCC 7820 from the Faculty of Biology, University of Lodz, Poland, were used as a test organism. The cultures were grown in 250-mL Erlenmeyer flasks containing $100 \mathrm{~mL}$ liquid BG-11 medium (Rippka et al. 1979) and incubated in a phytotron chamber. The Erlenmeyer flasks were maintained at 23/ $20{ }^{\circ} \mathrm{C}$ (light/dark) and a humidity of $30 \%$ in a phytotron chamber with alternating periods of light and dark $(12 \mathrm{~h} / 12 \mathrm{~h})$. Irradiance was held at $60 \mu \mathrm{mol}$ photons $\mathrm{m}^{-2} \mathrm{~s}^{-1}$. The $\mathrm{pH}$ (7.64 \pm 0.02$)$ of the medium was adjusted using $1 \mathrm{M} \mathrm{HCl}$ and/or $\mathrm{NaOH}$ solutions. All flasks were shaken at least three times a day to prevent clumping of cells. The initial algal density was $2 \times 10^{5}$ cells $\mathrm{mL}^{-1}$.

\section{Experimental setup}

Experiments were performed to study the toxic effect of hormones on $M$. aeruginosa. Hormones were added to each treatment flask separately (E1, E2, E3, EE2, PRO, PRE, LG, and TST) and then mixed (MIX1, MIX2, and MIX3) at different nominal concentration levels: $0.1,1,10,25,50,75$, and $100 \mathrm{mg} \mathrm{L}^{-1}$. All the investigated hormones were dissolved in methanol and added to the $100 \mathrm{~mL}$ of test medium containing M. aeruginosa cells to achieve the desired series of concentrations. Treatments with an equivalent amount of methanol, but without the presence of hormones, were included as control samples, which were cultured in the same conditions. MIX1 comprises all the tested compounds (E1, E2, E3, EE2, PRO, PRE, TST, LG), MIX2 one of the most toxic estrogens, progestogen, and androgen (EE2, PRO, TST), and MIX3 one of the most toxic hormones and three with the weakest effect (PRO, E1, E3, LG). MIX1, MIX2, and MIX3 were prepared with 1/8, $1 / 3$, and $1 / 4$ of each compound $\left(\mathrm{mg} \mathrm{mL}^{-1}\right.$ ), respectively, to achieve the same final concentration to be tested for individual hormones. The concentrations of hormones in the final experiment were established through a preliminary test. All the treatments were measured at $1,2,3,7,8,10,13$, and 14 days.

\section{Determination of biomass and chlorophyll $a$ content}

Biomass and chlorophyll $a$ concentrations were measured over 14 days in cultures containing different concentrations of hormones. Biomass was determined according to the modified method of Moheimani et al. (2013). For gravimetric measurement of dry weight, $10 \mathrm{~mL}$ of culture was filtered 
through pre-weighed and pre-combusted nylon membrane filters ( $3 \mu \mathrm{m}$, diameter $47 \mathrm{~mm}$, Yeti, Germany). The filters were then dried in an oven for $1 \mathrm{~h}$ at $105^{\circ} \mathrm{C}$ to a constant weight and weighed again. Chlorophyll $a$ concentrations were evaluated using an AlgaeChek Ultra fluorometer with fluorescence detection at $685 \mathrm{~nm}$ (Modern Water, UK).

\section{Statistical analysis}

The experiments were carried out five times for all treatments, and the results are presented as the means of five replicates (mean $\pm \mathrm{SD}, n=5$ ). Experimental data were analyzed with Microsoft Excel software package (Microsoft Corporation, USA) and Statistica (StatSoft) software. Identification and rejection of outliers were tested using the Q-Dixon test (Dixon 1953). Differences between M. aeruginosa cultures were considered to be significant at $P<0.05$.

The $\mathrm{EC}_{50}$ values and dose-response equation for 7,10 , 14 days were calculated using linear regression analysis of log-transformed concentration versus $\%$ of inhibition using the Microsoft Excel software package.

\section{Results}

\section{Chronic toxicity of single hormones}

The toxic effect of single and mixed hormones on the growth of $M$. aeruginosa was determined based on biomass and chlorophyll $a$ measurements at different concentrations of hormones during 14 days of exposure. The results are shown in Figs. 1 and 2 and Supplementary Material S1. Figure 1 shows the variability of biomass content in cyanobacteria cells during 14 days of exposure to increasing concentrations of hormones. The results obtained from the determination of biomass showed that eight of the investigated hormones were toxic to the studied $M$. aeruginosa. A concentrationdependent decrease in the biomass content was observed, which confirmed the growth-inhibiting effect of single hormones. Compared with the controls, $10-100 \mathrm{mg} \mathrm{L}^{-1}$ of $17-\alpha$-ethinylestradiol and progesterone significantly inhibited the growth of cyanobacteria $(P<0.05)$, while 0.1 and $1 \mathrm{mg} \mathrm{L}{ }^{-1}$ of EE2 and $0.1 \mathrm{mg} \mathrm{L}^{-1}$ of PRO resulted in a growth-stimulating effect after 7 days of exposure (Fig. $1 \mathrm{~d}, \mathrm{e})$. In the case of 17ß-estradiol, 5-pregnen-3 $\beta$-ol-20-one, and testosterone, the growth inhibition of cyanobacteria cultures was significantly lower than that of 17- $\alpha$ ethinylestradiol and progesterone. Nevertheless, these hormones inhibited the growth of $M$. aeruginosa at all concentration levels after 7 days of exposure (Fig. 1b, f, and h). In contrast, exposure to estrone, estriol, and levonorgestrel showed a weak effect on the growth of the cyanobacteria (Fig. 1a, c, and g).
Chlorophyll plays an important role in photosynthesis, because it absorbs light energy, which is then converted into the chemical energy associated with biomass. Therefore, chlorophyll content is an important index of algal activity. Similar decreasing trends were observed for the chlorophyll $a$ concentration of the exposed cells of M. aeruginosa. Within 14 days of incubation of cyanobacteria cultures in the presence of hormones, the content of chlorophyll $a$ pigment decreased with increasing exposure for all concentrations of the investigated compounds (Supplementary Material S1).

The $\mathrm{EC}_{50}$ values of the eight single hormones are presented in Table 1. In the case of almost all the examined hormones, the toxicity increased with time (E2, EE2, PRO, PRE, TST). The 14-day $\mathrm{EC}_{50}$ values of hormones to cyanobacteria ranged from 88.92 to $355.15 \mathrm{mg} \mathrm{L}^{-1}$. Of the various examined hormones, the sensitivity of $M$. aeruginosa to $17-\alpha$-ethinylestradiol and progesterone (88.92, $93.63 \mathrm{mg} \mathrm{L}^{-1}$, respectively) was the highest. The cyanobacteria were medium sensitive to $17 ß$-estradiol, 5 pregnen-3 $\beta$-ol-20-one, and testosterone (106.04, $141.84 \mathrm{mg} \mathrm{L}^{-1}$, respectively) and the least sensitive to estrone, estriol, and levonorgestrel (276.68, 355.15, $354.75 \mathrm{mg} \mathrm{L}^{-1}$, respectively). As is evident from Table 1 ( 14 days, $\mathrm{EC}_{50}$ ), the toxicity of hormones to Microcystis aeruginosa decreased in the order: EE2 > PRO $>$ E2 $>$ PRE $>$ TST $>$ E1 > LG $>$ E3.

\section{Chronic toxicity of mixed hormones}

The inhibitory effects of mixed hormones on biomass content in M. aeruginosa cultures after 14 days of exposure are shown in Fig. 2. The examined cyanobacteria were adversely affected by exposure to mixed hormones. Of all the investigated mixed hormones, the strongest inhibitory effects were observed for all concentrations of MIX1, even after only 3 days of exposure (Fig. 2a). A similar trend was observed in the case of MIX2, which inhibited the growth of $M$. aeruginosa at a concentration of 1-100 $\mathrm{mg} \mathrm{L}^{-1}$ after the third day (Fig. 2b). Among the mixed hormones, the weakest inhibition was observed after exposition to MIX3. This mixture inhibited the growth at a concentration of $75-100 \mathrm{mg} \mathrm{L}^{-1}$ after 7 days. Concentrations below $10 \mathrm{mg} \mathrm{L}^{-1}$ stimulated the growth of M. aeruginosa after 8 days of exposure (Fig. 2c).

The toxic effect increased with increasing concentrations of the tested mixtures. $\mathrm{EC}_{50}$ values of all mixed hormones decreased with time (Table 1). The range of $\mathrm{EC}_{50}$ values of mixed hormones varied from 56.66 (14 days) to $261.29 \mathrm{mg} \mathrm{L}^{-1}$ (7 days). Fourteen-day $\mathrm{EC}_{50}$ values for MIX1 (56.66 mg L ${ }^{-1}$ ) and MIX2 (72.71 $\mathrm{mg} \mathrm{L}^{-1}$ ) were lower than those for MIX3 $\left(166.83 \mathrm{mg} \mathrm{L}^{-1}\right)$, indicating the greater toxicity of MIX1 and MIX2. In brief, the following order of toxicity was observed: MIX1 > MIX2 > MIX3. 
Fig. 1 Changes in biomass content $\left(\mathrm{mg} \mathrm{L}^{-1}\right)$ of Microcystis aeruginosa during 14 days of exposure to $0.1,1,10,25,50,75$, and $100 \mathrm{mg} \mathrm{L}^{-1}$ single hormones (a E1, b E2, c E3, dEE2, e PRO, f PRE, g LG, h TST). Error bars represent the standard deviation of five measurements $(P<0.05$, $n=5$ )
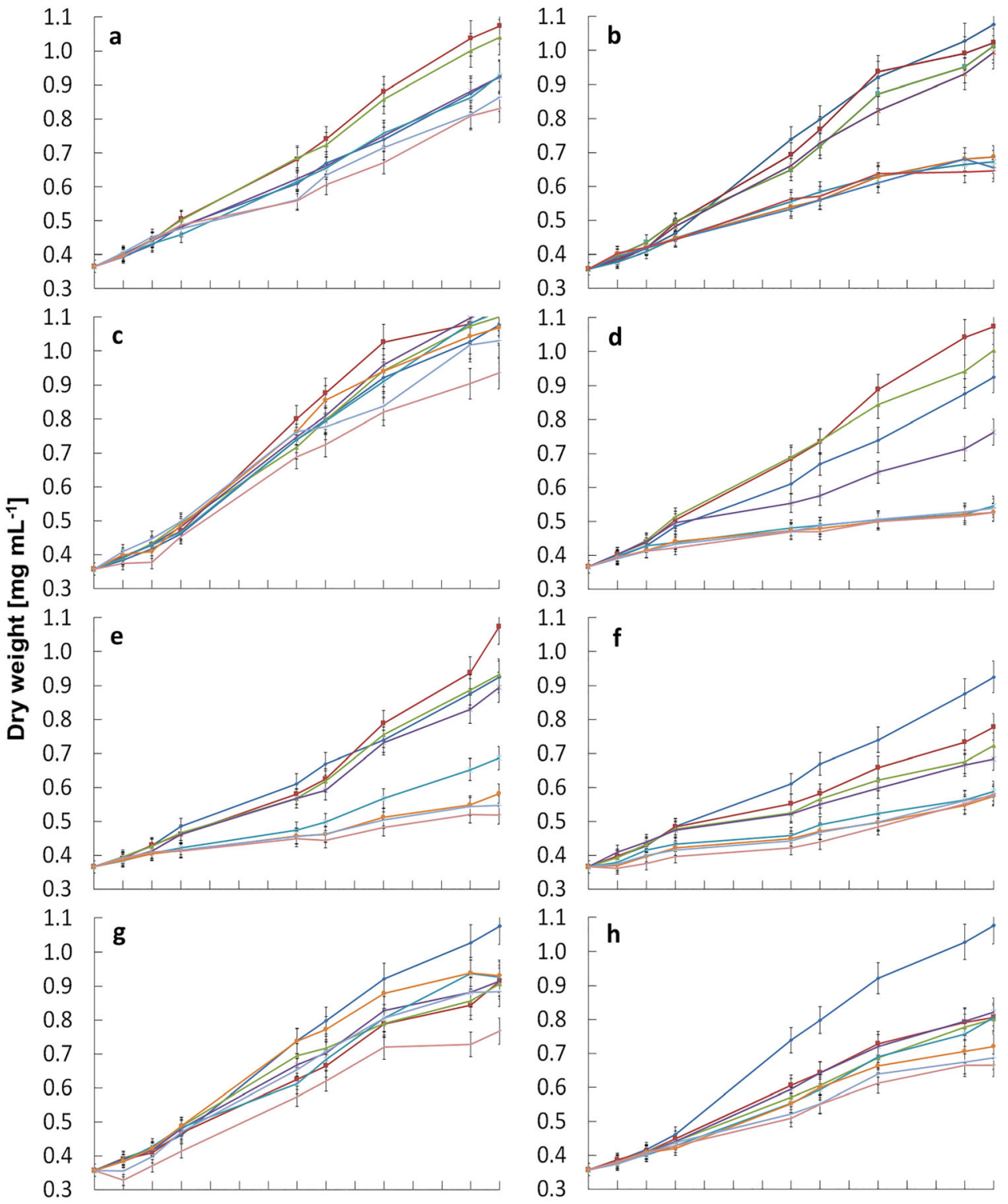

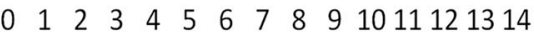

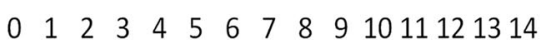

Time of exposure [days]

$\rightarrow$ control sample $\rightarrow-0.1 \rightarrow 1-10 \rightarrow 25 \rightarrow 50 \rightarrow 75-100$

\section{Discussion}

In recent years, hormones have attracted considerable attention due to their rapidly rising concentrations in lakes and rivers all over the world (Adeel et al. 2017). It is well known that hormones pose serious threats to soil, plants, the aquatic environment, and humans, and negatively affect many aquatic organism species, such as amphibians and fish (Yuan et al. 2014). Less is known about the impact of hormones on microalgae. The research that can be found in literature focuses on studying the effect of EE2 on algal growth. The effects of single and mixed hormones on the cyanobacterium
M. aeruginosa were explored for the first time in this study. Balina et al. (2015) found that $100-500 \mu \mathrm{g} \mathrm{L}^{-1}$ of $17-\alpha$ ethinylestradiol causes a $100 \%$ reduction in the growth rate and induces the initial destruction of algae cells. Similar results were obtained by Pocock and Falk (2014). In their study, the growth of green algae Chlamydomonas reinhardtii was negatively affected by EE2 and $7 \mu \mathrm{M}$ of this hormone reduced the growth rate by $68 \%$ compared with the control sample. Liu et al. (2010) reported that the $\mathrm{EC}_{50}$ values in a Navicula incerta growth inhibition test for EE2 and E2 were 3.21 and $>10 \mathrm{mg} \mathrm{L}^{-1}$, respectively. Salomao et al. (2014) studied the effect of E1, E2, and EE2 on Desmodesmus subspicatus and 
Fig. 2 Changes in biomass content $\left(\mathrm{mg} \mathrm{L}^{-1}\right)$ of Microcystis aeruginosa during 14 days of exposure to $0.1,1,10,25,50,75$, and $100 \mathrm{mg} \mathrm{L}^{-1}$ mixed hormones (a MIX1, b MIX2, c MIX3). Error bars represent the standard deviation of five measurements $(P<0.05, n=5)$
1.0
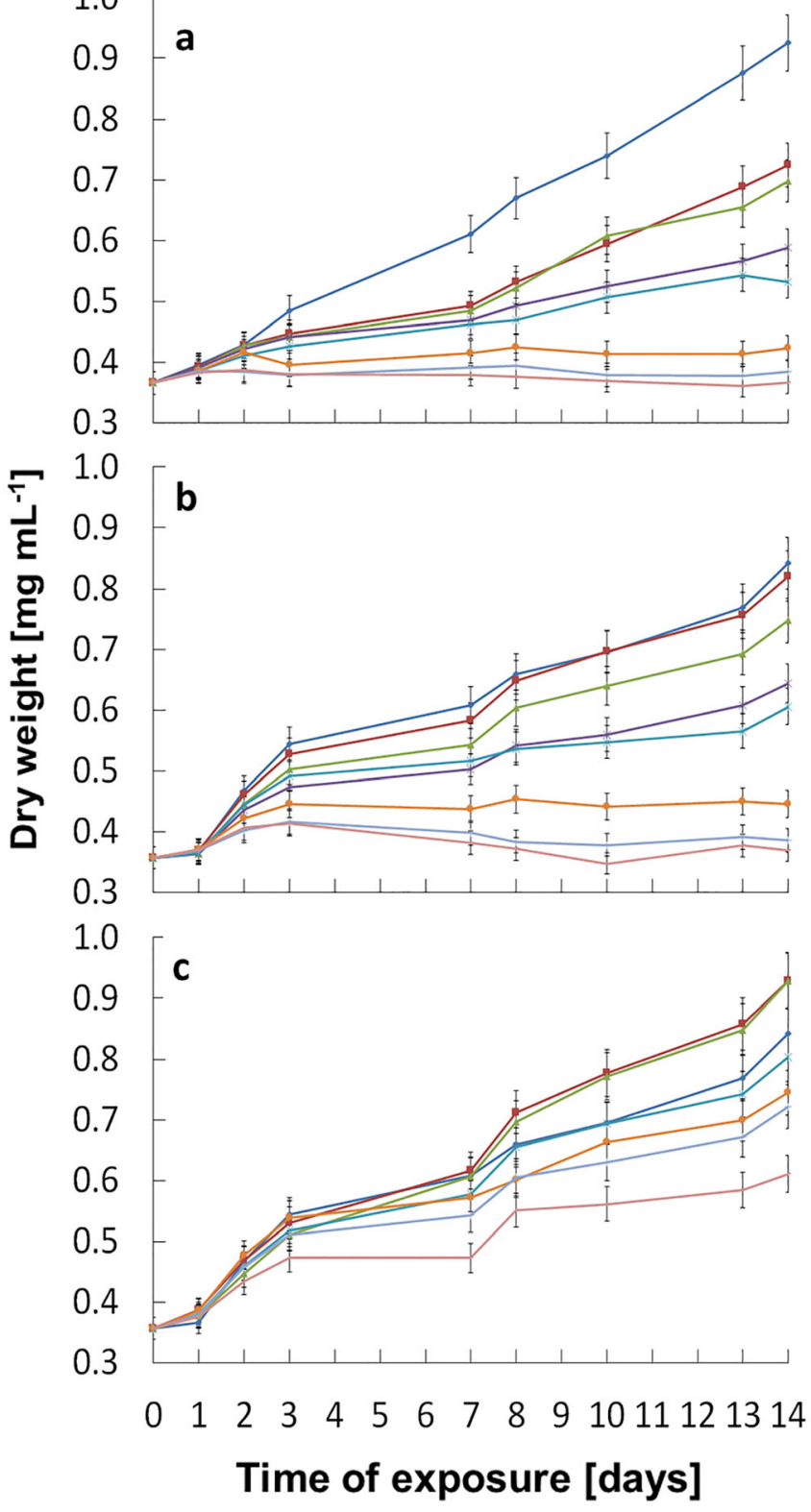

$\rightarrow$ control sample $=0.1+1 * 10 * 25 \rightarrow 50+75-100$
Pseudokirchneriella subcapitata. Their results show that $17-\alpha$-ethinylestradiol and $17 \beta$-estradiol were more toxic than estrone to both algae species. The results obtained in the present study confirm that the toxicity of estrogens toward M. aeruginosa decreased in the order: EE2 $>$ E2 $>$ E1. However, the achieved $\mathrm{EC}_{50}$ values were significantly higher than in the case of studies by other scientists. This difference results from the different culture conditions and different species of test organisms. Peng et al. (2014) indicated that low concentrations, such as $1.6 \mu \mathrm{M}$, of progesterone and norgestrel did not significantly affect the growth of Scenedesmus obliquus and Chlorella pyrenoidosa. Lai et al. (2002), Della Greca et al. (2008), and Maes et al. (2014) studied biotransformation of 17- $\alpha$-ethinylestradiol by microalgae, and the obtained results showed that a low concentration of pollutants did not affect growth. As in the case of the above-mentioned studies, in the present research, low concentrations $\left(0.1-1 \mathrm{mg} \mathrm{L}^{-1}\right)$ of E2, PRE, LG, and TST did not significantly affect the growth of $M$. aeruginosa. Cheng et al. (2018) reported that $0.01-5 \mathrm{mg} \mathrm{L}^{-1}$ of 17 - $\alpha$-ethinylestradiol stimulated the growth of microalgae mutant Chlorella PYZU1. However, this growth-stimulating effect decreased with increasing concentrations of the pollutant. Low-dose stimulation and high-dose inhibition are associated with the occurrence of the phenomenon of hormesis (Calabrese and Baldwin 2003; Calabrese 2005). Low concentrations of hormones can 


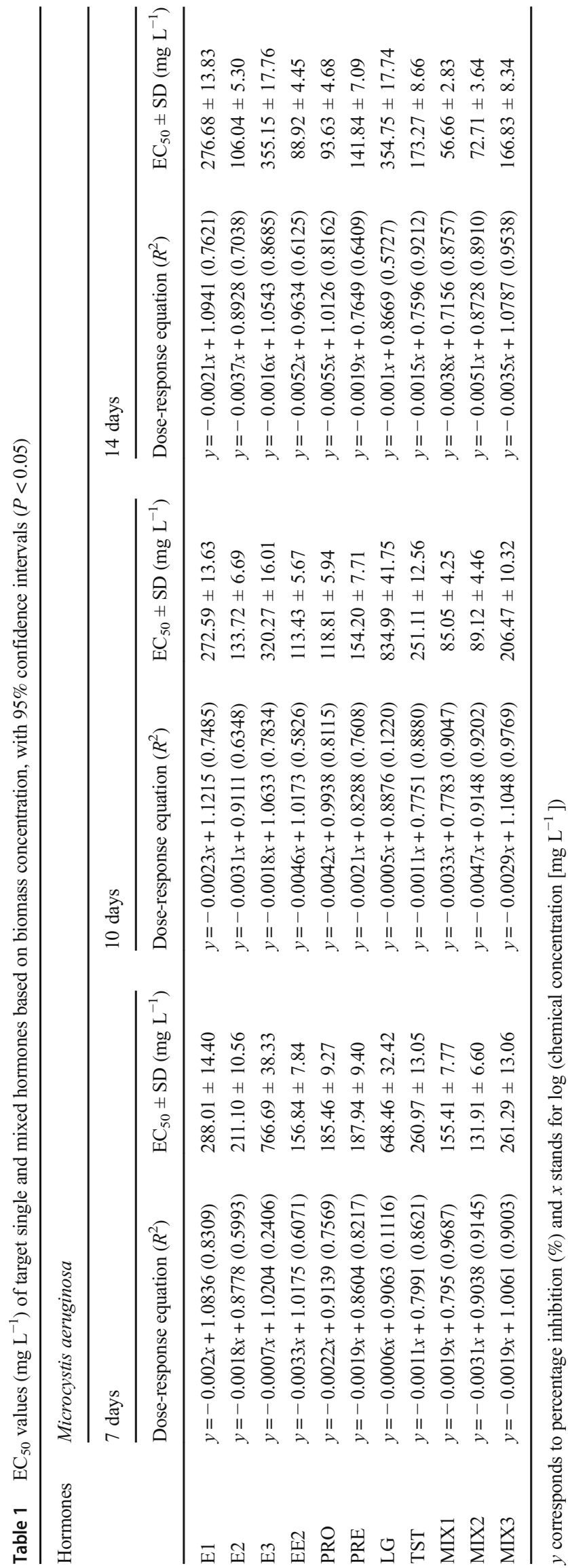

activate the maintenance and repair functions of cyanobacteria cells by increasing the activity of proteins involved in their protection. In contrast, higher concentrations inhibit growth because they damage the functions of maintenance and repair of cells. A similar phenomenon was observed in our study because low concentrations of E1, E3, EE2, and PRO stimulated the growth of $M$. aeruginosa. Previous studies have shown that hormones inhibited the growth of cyanobacteria Anabaena variabilis (Czarny et al. 2019a). Similar to the present study, EE2 and PRO were the most toxic of all the tested hormones and the achieved 14-day $\mathrm{EC}_{50}$ values were 48.59 and $82.95 \mathrm{mg} \mathrm{L}^{-1}$. PRE, TST, and E2 were moderately toxic to these cyanobacteria (14-day $\mathrm{EC}_{50}, 283.50,336.68$, and $437.82 \mathrm{mg} \mathrm{L}^{-1}$ ), while E1, E3, and LG did not affect their growth. The toxicity of hormones to Anabaena variabilis seems to be similar as for M. aeruginosa. However, $M$. aeruginosa was less sensitive to $17-\alpha$-ethinylestradiol and progesterone and more toxic to estrone, $17 \beta$-estadiol, estriol, 5-pregnen-3 $\beta$-ol-20-one, levonorgestrel, and testosterone.

According to the literature, the toxic effects of single hormones on the growth of cyanobacteria have been tested, and the effects of mixtures have not been evaluated. The only information about the toxic effects of mixtures of hormones on microalgae can be found in the previous research which concerned the estimation of their effect on the cyanobacterium A. variabilis and the green algae C. vulgaris and Scenedesmus armatus (Czarny et al. 2019a, b). The achieved 14-day $\mathrm{EC}_{50}$ values for mixed hormones for A. variabilis, $C$. vulgaris, and S. armatus were $37.00-89.46,47.89-75.30$, and 70.54$697.26 \mathrm{mg} \mathrm{L}^{-1}$, respectively (Czarny et al. 2019a, b). Comparing the results, it can be estimated that M. aeruginosa were less sensitive than A. variabilis and C. vulgaris, and more sensitive than S. armatus. The toxicity of the three mixtures of hormones to M. aeruginosa was MIX1 > MIX2 > MIX3. The much higher toxicity of MIX1 and MIX2 to cyanobacteria compared with MIX3 might be related to the components of the mixtures. The strongest inhibitory effect on M. aeruginosa was observed for EE2 and PRO. It is known that compounds in a mixture can interact with each other, which can result in a stronger (synergistic) or weaker (antagonistic) combined effect than could be expected from the toxicity data of each hormone alone. A more than additive effect arises when the combined effect of pollutants is greater than the sum of the effects of each compound individually (Nielsen et al. 2008). In our study, the sum of the $\mathrm{EC}_{50}$ values of single components was greater than the obtained values for mixtures. Therefore, the interactions between hormones result in a more than additive effect.

The toxic effect on M. aeruginosa might be related to several factors and mechanisms occurring simultaneously. Even if non-target organisms, such as cyanobacteria, do not have an endocrine system, hormones can affect their growth. It is 
known that compounds with an octanol/water partition coefficient $(\log \mathrm{P})>3$ show high lipophilicity and high bioaccumulation potential (Silva et al. 2012; Blewett et al. 2014; Czarny et al. 2017). The octanol/water partition coefficients of almost all tested hormones were above 3, except for estriol (2.4) (Aris et al. 2014; Ismail et al. 2017). For this reason, hormones can easily cross cell membranes of cyanobacteria. Perron and Juneau (2011) reported that EDCs such as 17ßestradiol can alter energy flows through photosystem II and affect the photosynthetic activity of $M$. aeruginosa and the green algae $C$. reinhardtii and $P$. subcapitata. Many studies have confirmed that the difference in the toxicity of endocrinedisrupting chemicals varies widely between species (Perron and Juneau 2011; Salomao et al. 2014; Xiang et al. 2018).

Environmental levels of hormones in typical lakes and rivers from different countries fluctuate in the range of ng $\mathrm{L}^{-1}$ (Adeel et al. 2017; Ma and Yates 2018). The ecological risk of these compounds can be assessed by comparing the measured environmental concentrations and the $\mathrm{EC}_{50}$ values obtained in this study. The results indicate that single and mixed hormones posed no risk to aquatic life such as cyanobacteria. However, taking into account the growing environmental pollution resulting from the increase in the amount of hormones, a much higher risk for aquatic organisms is anticipated.

\section{Conclusions}

In this study, the toxicity of eight single and three mixed hormones to Microcystis aeruginosa was compared based on biomass, chlorophyll $a$ content, and $\mathrm{EC}_{50}$ values. Among all the examined single hormones, the sensitivity of the cyanobacterium $M$. aeruginosa to 17- $\alpha$ ethinylestradiol and progesterone was the highest. In contrast, 17ß-estradiol, 5-pregnen-3 $\beta$-ol-20-one, and testosterone were moderately toxic and estrone, estriol, and levonorgestrel showed the weakest effect. The achieved 14day $\mathrm{EC}_{50}$ values were from 88.92 to $355.15 \mathrm{mg} \mathrm{L}^{-1}$. Moreover, mixed hormones are more toxic than single compounds. MIX1 and MIX2 were more toxic than MIX3 (56.66, 72.72, $166.83 \mathrm{mg} \mathrm{L}^{-1}$, respectively). According to the obtained $\mathrm{EC}_{50}$ values, more than additive effect between hormones may occur, especially when mostly toxic compounds (17- $\alpha$-ethinylestradiol and progesterone) were the dominant pollutant in the mixture. Therefore, the increased toxicity caused by combined hormones poses a greater risk for the aquatic environment. According to the European Union classification, pollutants with $\mathrm{EC}_{50}$ values of $10-100 \mathrm{mg} \mathrm{L}^{-1}$ were considered harmful to aquatic organisms, while those with $\mathrm{EC}_{50}$ values above $100 \mathrm{mg} \mathrm{L}^{-1}$ were not classified. Therefore EE2, PRO, MIX1, and MIX2 may be considered harmful to $M$. aeruginosa. This is the first study to compare the toxic effect of hormones and their mixtures on the growth of $M$. aeruginosa. The measured concentrations of hormones in samples of river and lake water collected in several countries were below the tested concentrations, indicating that these compounds pose a negligible risk to cyanobacteria.

Open Access This article is distributed under the terms of the Creative Commons Attribution 4.0 International License (http:// creativecommons.org/licenses/by/4.0/), which permits unrestricted use, distribution, and reproduction in any medium, provided you give appropriate credit to the original author(s) and the source, provide a link to the Creative Commons license, and indicate if changes were made.

\section{References}

Adeel M, Song X, Wang Y, Francis D, Yang Y (2017) Environmental impact of estrogens on human, animal and plant life: a critical review. Environ Int 99:107-119

Annamalai J, Namasivayam V (2015) Endocrine disrupting chemicals in the atmosphere: their effects on humans and wildlife. Environ Int 76: 78-97

Aris AZ, Shamsuddin AS, Praveena SM (2014) Occurrence of $17 \alpha$ ethynylestradiol (EE2) in the environment and effect on exposed biota: a review. Environ Int 69:104-119

Balina K, Balode M, Muzikante L, Blumberga D (2015) Impact of synthetic hormone $17 \alpha$-ethinylestradiol on growth of microalgae Desmodesmus communis. Agron Res 13:445-454

Barber LB, Murphy SF, Verplanck PL, Sandstrom MW, Taylor HE, Furlong ET (2006) Chemical loading into surface water along a hydrological, biogeochemical, and land use gradient: a holistic watershed approach. Environ Sci Technol 40:475-486

Barber LB, Keefe SH, Leblanc DR, Bradley PM, Chapelle FH, Meyer MT, Loftin KA, Kolpin DW, Rubio F (2009) Fate of sulfamethoxazole, 4-nonylphenol, and $17 \beta$-estradiol in groundwater contaminated by wastewater treatment plant effluent. Environ Sci Technol 43:4843-4850

Benotti MJ, Snyder SA (2009) Pharmaceuticals and endocrine disrupting compounds: implications for ground water replenishment with recycled water. Ground Water 47:499-502

Blewett TA, Chow TL, MacLatchy DL, Wood CM (2014) A species comparison of 17- $\alpha$-ethynylestradiol uptake and tissue-specific distribution in six teleost fish. Comp Biochem Physiol C 161:33-40

Brian JV, Harris CA, Scholze M, Kortenkamp A, Booy P, Lamoree M, Pojana G, Jonkers N, Marcomini A, Sumpter JP (2007) Evidence of estrogenic mixture effects on the reproductive performance of fish. Environ Sci Technol 41:337-344

Calabrese EJ (2005) Paradigm lost, paradigm found: the re-emergence of hormesis as a fundamental dose response model in the toxicological sciences. Environ Pollut 138:378-411

Calabrese EJ, Baldwin LA (2003) The hormetic dose-response model is more common than the threshold model in toxicology. Toxicol Sci 71:246-250

Chang H, Wan Y, Wu S, Fan Z, Hu J (2011) Occurrence of androgens and progestogens in wastewater treatment plants and receiving river waters: comparison to estrogens. Water Res 45:732-740 
Cheng J, Ye Q, Li K, Liu J, Zhou J (2018) Removing ethinylestradiol from wastewater by microalgae mutant Chlorella PY-ZU1 with $\mathrm{CO}_{2}$ fixation. Bioresour Technol 249:284-289

Czarny K, Szczukocki D, Krawczyk B, Zielinski M, Miekos E, GadzalaKopciuch R (2017) The impact of estrogens on aquatic organisms and methods for their determination. Crit Rev Environ Sci Technol 47:909-963

Czarny K, Szczukocki D, Krawczyk B, Skrzypek S, Miekos E, GadzalaKopciuch R (2019a) Inhibition of growth of Anabaena variabilis population by single and mixed steroid hormones. J Appl Phycol 31: 389-398

Czarny K, Szczukocki D, Krawczyk B, Skrzypek S, Zielinski M, Gadzala-Kopciuch R (2019b) Toxic effects of single animal hormones and their mixtures on the growth of Chlorella vulgaris and Scenedesmus armatus. Chemosphere 224:93-102

Della Greca M, Pinto G, Pistillo P, Pollio A, Previtera L, Temussi F (2008) Biotransformation of ethinylestradiol by microalgae. Chemosphere 70:2047-2053

Dixon WJ (1953) Processing data for outliers. Biometrics 9:74-89

Gorga M, Insa S, Petrovic M, Barcelo D (2015) Occurrence and spatial distribution of EDCs and related compounds in waters and sediments of Iberian rivers. Sci Total Environ 503-504:69-86

He H, Wang C, Tang Q, Yang F, Xu Y (2018) Elucidation of possible molecular mechanisms underlying the estrogen-induced disruption of cartilage development in zebrafish larvae. Toxicol Lett 289:22-27

Ismail NAH, Wee SY, Aris AZ (2017) Multi-class of endocrine disrupting compounds in aquaculture ecosystems and health impacts in exposed biota. Chemosphere 188:375-388

Jia Y, Hammers-Wirtz M, Crawford SE, Chen Q, Seiler TB, Schaffer A, Hollert H (2019) Effect-based and chemical analyses of agonistic and antagonistic endocrine disruptors in multiple matrices of eutrophic freshwaters. Sci Total Environ 651(Pt 1):1096-1104

Khanal SK, Xie B, Thompson ML, Sung S, Ong SK, Van Leeuwent J (2006) Fate, transport, and biodegradation of natural estrogens in the environment and engineered systems. Environ Sci Technol 40: $6537-6546$

Lai KM, Scrimshaw MD, Lester JN (2002) Biotransformation and bioconcentration of steroid estrogens by Chlorella vulgaris. J Appl Environ Microbiol 68:859-864

Laurenson JP, Bloom RA, Page S, Sadrieh N (2014) Ethinyl estradiol and other human pharmaceutical estrogens in the aquatic environment: a review of recent risk assessment data. AAPS J 16:299-310

Leet JK, Gall HE, Sepulveda MS (2011) A review of studies on androgen and estrogen exposure in fish early life stages: effects on gene and hormonal control of sexual differentiation. J Appl Toxicol 31:379 398

Leonard JA, Cope WG, Hammer EJ, Barnhart MC, Bringolf RB (2017) Extending the toxicity-testing paradigm for freshwater mussels: assessing chronic reproductive effects of the synthetic estrogen $17 \alpha$-ethinylestradiol on the unionid mussel Elliptio complanata. Comp Biochem Physiol C 191:14-25

Li Z, Xiang X, Li M, Ma Y, Wang J, Liu X (2015) Occurrence and risk assessment of pharmaceuticals and personal care products and endocrine disrupting chemicals in reclaimed water and receiving groundwater in China. Ecotoxicol Environ Saf 119:74-80

Liu Y, Guan Y, Gao Q, Tam NF, Zhu W (2010) Cellular responses, biodegradation and bioaccumulation of endocrine disrupting chemicals in marine diatom Navicula incerta. Chemosphere 80: 592-599

Luo Z, Tu Y, Li H, Qiu B, Liu Y, Yang Z (2019) Endocrine-disrupting compounds in the Xiangjiang River of China: spatio-temporal distribution, source apportionment, and risk assessment. Ecotoxicol Environ Saf 167:476-484

Ma L, Yates SR (2018) Dissolved organic matter and estrogen interactions regulate estrogen removal in the aqueous environment: a review. Sci Total Environ 640-641:529-542
Maes HM, Maletz SX, Ratte HT, Hollender J, Schaeffer A (2014) Uptake, elimination, and biotransformation of $17 \alpha$-ethinylestradiol by the freshwater alga Desmodesmus subspicatus. Environ Sci Technol 48:12354-12361

Matsushima A (2018) A novel action of endocrine-disrupting chemicals on wildlife; DDT and its derivatives have remained in the environment. Int J Mol Sci 19. https://doi.org/10.3390/ijms19051377

Moheimani NR, Borowitzka MA, Isdepsky A, Fon Sing S (2013) Standard methods for measuring growth of algae and their composition. In: Borowitzka MA, Moheimani NR (eds) Algae for biofuels and energy. Springer, Cham, pp 265-283

Nie M, Yan C, Dong W, Liu M, Zhou J, Yang Y (2015) Occurrence, distribution and risk assessment of estrogens in surface water, suspended particulate matter, and sediments of the Yangtze Estuary. Chemosphere 127:109-116

Nielsen E, Ostergaard G, Larsen JC (2008) Toxicological risk assessment of chemicals. Informa Healthcare, New York

Peng FQ, Ying GG, Yang B, Liu S, Lai HJ, Liu YS, Chen ZF, Zhou GJ (2014) Biotransformation of progesterone and norgestrel by two freshwater microalgae (Scenedesmus obliquus and Chlorella pyrenoidosa): transformation kinetics and products identification. Chemosphere 95:581-588

Perron MC, Juneau P (2011) Effect of endocrine disrupters on photosystem II energy fluxes of green algae and cyanobacteria. Environ Res 111:520-529

Pocock T, Falk S (2014) Negative impact on growth and photosynthesis in the green alga Chlamydomonas reinhardtii in the presence of the estrogen 17 $\alpha$-ethynylestradiol. PLoS One 9:e109289

Pojana G, Gomiero A, Jonkers N, Marcomini A (2007) Natural and synthetic endocrine disrupting compounds (EDCs) in water, sediment and biota of a coastal lagoon. Environ Int 33:929-936

Rippka R, Deruelles J, Waterbury JB, Herdman M, Stranier RY (1979) Genetic assignments, strain histories and properties of pure cultures of cyanobacteria. J Gen Microbiol 11:1-61

Salomao AL, Soroldoni S, Marques M, Hogland W, Bila DM (2014) Effects of single and mixed estrogens on single and combined cultures of D. subspicatus and P. subcapitata. Bull Environ Contam Toxicol 93:215-221

Silva CP, Otero M, Esteves V (2012) Processes for the elimination of estrogenic steroid hormones from water: a review. Environ Pollut 165:38-58

Thrupp TJ, Runnalls TJ, Scholze M, Kugathas S, Kortenkamp A, Sumpter JP (2018) The consequences of exposure to mixtures of chemicals: something from 'nothing' and 'a lot from a little' when fish are exposed to steroid hormones. Sci Total Environ 619-620: $1482-1492$

Wang X, Zhang R, Zhang H, Wang Y (2017) The occurrence, exposure and risk assessment of perfluoroalkyl acids in food from mainland, China. Food Addit Contam A 34:1990-1998

Xiang R, Shi J, Yu Y, Zhang H, Dong C, Yang Y, Wu Z (2018) The effect of bisphenol a on growth, morphology, lipid peroxidation, antioxidant enzyme activity, and PS II in Cylindrospermopsis raciborskii and Scenedesmus quadricauda. Arch Environ Contam Toxicol 74: 515-526

Yu Y, Wu L, Chang AC (2013) Seasonal variation of endocrine disrupting compounds, pharmaceuticals and personal care products in wastewater treatment plants. Sci Total Environ 442:310-316

Yuan XY, Li TY, Zhou L, Zhao XQ (2014) Characteristics and risk assessment of estrogenic compounds in rivers of Southern Jiangsu Province, China. IERI Proc 9:176-184

Publisher's note Springer Nature remains neutral with regard to jurisdictional claims in published maps and institutional affiliations. 